\title{
Atualização Administrativa
}

\author{
Márcio Tomelim \\ Coordenador do mestrado em administração da UnB \\ Doutor em Administração Pública pela Universidade de Paris
}

\section{Introdução}

A evolução da divisão do trabalho produziu a organização formal no contexto de regras e principios para alcançar os objetivos colimados, com menor número de pessoas, menor capital empregado, obtendo maior produtividade da terra empregada, utilizando maior quantidade de matériasprimas, demandando maior quantidade de serviços, instrumentalizado no conhecimento científico e técnico. A tríade composição dos fatores de produção, presentes na organização, adota um elemento fixo do respectivo setor econômico (terra, matériasprimas, serviços ou o componente ciência e tecnologia do setor quaternário) ao qual adiciona-se em quantidade o capital, mas soma-se em qualidade a mão-de-obra empregada.

O instrumental de
atualização das estruturas
organizacionais, a partir de
suas forças internas, cria ım!
desenvolvimento
auto-sustentudo das
instituiçóes

Assim, a composiçio tríade desses elementos, na dinâmica própria de cada organização, tem ações resultantes do contexto aonde está inserida, com predominância de sociedades com valores próprios no tempo/espaço. Este periodo deferido no espaço produziu sociedades de poder econômico e poder político, prevendo-se no processo evolutivo das sociedades aquelas derivadas do poder cientifico.

O fator de produção mão-de-obra constitui a determinante na organiza- çào, da concepção à execução. As relações sociais na escala espaço/tempo da evolução da humanidade produziu e ainda produz, o aperfeiçoamento na acumulação dos conhecimentos, criando as diferenças de povos e raças na organização do Estado/Nação.

O prêmio nobel de Economia, Theodore W. Schultz confirma o valor da mão-de-obra, quando diz que "uma economia dinâmica só pode ser lançada e sustentada através do esforço de homens de todos os níveis sociais que contenham tanto aprendizagem convencional quanto aptidões manipuladas de técnicas".(1)

A formaçào de recursos humanos na organizaçĩo do Estado/Nação, nào precisa ser considerada como privilégio de paises ricos, em recursos naturais, mas qualquer nação de espaço/tcmpo inteligentemente ordenado deve saber usar suas melhores inicligências, para a condução de Administraçà Pública voltada para a siltisfaçào das necessidades do povo Ila sua totalidade.

As organizações oriundas no movimento oxógeno inicialmente, começam a ter consistência e dinâmica própria, quando iniciam o processo endógeno de produção de um desenvolvimento auto-sustentado.

O segmento Administração Pública, no Brasil, tem procurado renovar as organizaçōes num movimento exógeno, seja através de reformas ou de ações de modernização. Nossa proposta de Atualização Administrativa prescreve o redirecionamento dos esforços, adotando-se movimentos endógenos mediante utilização de recursos humanos, como elemento propulsor das renovações. O instrumental de atualização das estruturas organiza- cionais a partir de suas forças internas, cria um desenvolvimento autosustentado das instituições.

Confirmamos na expressão de Massenet que a "perspectiva de colocar em movimento as organizações, não se trata mais de reformar, isto é, de reagir no abstrato, em nome de um modelo ideal pretendido, em uma realidade rebelde. Trata-se de colocar em movimento, e sobretudo tornar possível um movimento espontâneo das organizações públicas".(2)

Este movimento espontâneo é endógeno e não exógeno, daí o princípio do movimento ser de dentro para fora, através de seus próprios recursos humanos.

\section{Reforma}

A segunda República 1930/45 traz no seu bojo o intervencionismo estatal praticado em diversos países do mundo. Este intervencionismo obriga o Estado a assumir novas funções até então restritas do "laissez fraire, laissez passer" de um liberalismo amorfo. Reformar o Estado ou a estrutura da máquina governamental era uma necessidade imposta pela assunção das novas funçôes de Governo, própria de um modelo intervencionista.

As origens históricas dos
processos de reforma
remontam às épocas em que
se passou a conhecer a
administração como atividade
organizada

"Nessa época, mudou efetivamente o papel do Estado, até então um estado policial, que apenas regula- 


\section{IDÉIAS}

mentava a vida social e econômica do País. A partir de 1930 , vitoriosa a $\mathrm{Re}-$ volução, surgiu o Estado Intervencionista. O Presidente Getúlio Vargas procurou recompor o Estado Brasileiro, intervindo na vida econômica e social do Pais"'.(3)

Este processo intervencionista, copiado de paises mais adiantados como: Estados Unidos, Alemanha, Itália e outros, procurou introduzir no modelo brasileiro novas técnicas de gestão administrativa. O periodo de reforma que se inicia na Segunda República, tem seu apanágio na Terceiıa República de 1946/64, que na vigência da Constituiçâo de 1946 encontra na descentralização seu modelo.

Ao conceituar como "Reforma Administrativa", em setindo lato, qualquer esforço metodizado com o objetivo de aumentar a eficiência das organizações, o Prof. Allyson diz que as origens históricas dos processos de reforma remontam, assim, às épocas em que, em diferentes paises se passou a conhecer a administração como atividade organizada".(4)

Devemos evidenciar que, nesse período, a administraçâo pública federal não dispunha de um quadro de pessoal capaz de produzir as transformações necessárias para um Estado moderno. Assim, o processo de reformas se caracterizou pela produção de documentos de reforma de caráter exógeno, isto é: de fora para dentro, elaborados por empresas de consultoria, muitas vezes até estrangeiras. Esta característica de reformas de fora para dentro não atingia os objetivos pela falta de participação no processo das pessoas afetadas pela própria reforma, que somado à falta de quadros na Administração Pública tornava impossivel aplicar regras e técnicas preconizadas por empresas externas, que propunham práticas e valores incongruentes com a cultura da administração. Este periodo que chamamos de reforma, marchava tão lento que quando as novas regras e méto- dos eram introduzidos na Administração Pública, careciam de reforma das reformas.

\section{Modernização}

Na vigência da Quarta República 1964/85 - que produziu a sístole, pela centralização do poder do Estado - inicia-se um novo processo de reforma que foi normatizado em 1967 pelo Decreto-lei n. 200, trazendo no seu contexto histórico a modernização do Estado Brasileiro, pela cooptação de pessoal do setor privado para assumir funções no setor público.

O Decreto-lei n. 200 , trouxe para dentro do setor público a modernidade do setor empresarial

O processo de modernização administrativa, tinha nos dirigentes da época a consciência das dificuldades a serem enfrentadas, deixando lições que, se nâo justificam os erros e acertos, evidenciam um passo a mais no processo de reforma para se completar com novas técnicas de Atualização Administrativa, ora propostas.

Os dirigentes da SEMOR assim expressaram: (5)

a) a modernização do Serviço Público não pode ser, ao mesmo tempo, global e imediata. Há que estabelecer critérios de prioridade, tanto em função da escassez de recursos humanos e financeiros, quanto das conveniências de estratégia política que impōem gradualismo à reforma;

b) o processo de modernização deve ser permanente, e orientado por uma política global;

c) as alteraçōes de estruturas, ainda que às vezes necessárias ao longo de um processo de reforma, nâo representam isoladamente modernização;

d) é preciso explicitar clara e precisamente os propósitos do processo de mudança;

e) o processo de mudança não tem curso com abstração das pes- soas e organizações que são seu objeto e muito menos contra elas;

f) sem envolvimento dos dirigentes, em todos os niveis da administração, os esforços mais ambiciosos de modernização estão fadados à frustração.

Esta nova característica de ver a Administração Pública, trouxe para dentro do setor público a modernidade do setor empresarial, através dos dirigentes assim cooptados.

\section{Atualização}

A Atualização Administrativa pressupõe a existência de pessoal qualificado ou, na falta desta condição, a montagem de uma estrutura capaz de prepará-los. Com a transformação do DASP em SEDAP, levantou-se uma nova bandeira na Administração Pública de formaçâo e treinamento de gestores da função pública.

\section{A atualização administrativa tem a característica de preparar recursos humanos para o processo de reformar e modernizar o Estado: de dentro para fora, e de caráter permanente}

Na evolução da reforma e modernizaçâo, tivemos dois momentos de predominância de profissões de caráter corporativista, que marcavam ou davam a tônica da presença de certas profissões no setor público.

No primeiro período de reforma de 1930 a 1964, a presença dos bacharéis em direito produziu o Estado Legalista, caracterizado por uma estrutura DASPEANA.

No segundo período de 1964 até 1986, caracterizado pela modernização e tendo como estrutura base, inicialmente o Ministério do Planejamento e em seguida a Secretaria de Planejamento da Presidência da República via SEMOR - Secretaria de Modernização, de características de planejamento econômico, predominava os bacharéis em economia.

Estamos hoje, inaugurando uma terceira fase com a SEDAP - Secre- 


\section{IDÉIAS}

taria de Administração Pública da Presidência da República, através da Escola Nacional de Administração Pública, na qual a multidisciplinaridade de profissões pelo processo seletivo e estrutura curricular deverá dar ênfase à gestão das atividades do setor público: A predominância de um currículo voltado para a ciência administrativa deverá inaugurar este novo período, aberto à todas as profissões, acabando com o corporativismo profissional.

As atividades da FUNCEP Fundação Centro de Formação do Servidor Público foram afetadas com a incumbência do treinamento e formação do servidor público. O CEDAM - Centro de Desenvolvimento da Administração Pública, tem por função precípua o treinamento dos servidores públicos e a ENAP - Escola Nacional de Administração Pública, a função de preparar os gesto-. res da Administração Pública. Estas duas funções, que necessitam de uma implementação própria, poderão iniciar este novo processo de administrar, pela Atualização Administrativa.

A filosofia da Atualização Administrativa vem de encontro às atividades de reforma e modernizaçào, que não tiveram êxito exatamente por ser um processo exógeno no contexto dit administração, enquanto (yuc a Atualização Administrativa tem a caracteristica de ser um processo endógeno, isto é: preparar recursos humanos para o processo de reformat e modernizar de dentro para tora, c de caráter permanente. A Atualização Administrativa preconiza o estudo sistemático, de métodos e processos de eficiência e eficácia de aplicação constante na Administração Pública. A evolução tecnológica, com a introdução do computador nas tarefas da administração, novas tecnologias, pesquisadas ou traduzidas pelo estudo comparativo de outros países, são práticas que devem ser introduzidas, sem alarde, mas de maneira contínua e progressiva pela prática do treina- mento e formação permanente do administrador público.

Esta será a nova visão da Atualização Administrativa, que deixando tâneos de administrações sucessivas, deverá ser a prática constante de todos os dirigentes porque os dirigentes devem ter internalizado esta filosofia, pelo treinamento e formação contínua.

A dinâmica da sociedade, na época da simultaneidade das comunicações, deve fazer a história administrativa e não somente registrá-la.

$\mathrm{O}$ atingimento destas metas será possível com a integração da força renovada da Universidade, que deverá estar presente em programas e projetos de treinamento e formação.

Quando dissemos no livro "O Quaternário: Seu Espaço e Poder" que estamos no limiar da sociedade do conhecimento, a que damos o nome de sociedade quaternária, procuramos insistir na produção e na aquisição de conhecimentos como valor maior e como função capaz de dominar a dicotomia entre os aspectos culturais e utilitários. Na medida em que o setor quaternário absorver a maioria da populaçào escolarizada e ativa, esta se tornará a mola propulsora do desenvolvimento econômico e social.

Ao indicarmos a presença da Universidade no processo de Atualização Administrativa, queremos evidenciar ytie a Universidade e o Estado formam um binômio indissolúvel de criaçào, de desenvolvimento de regras c princípios que quando aplicados convenientemente conduzem a sociedade a produzir mais e mais eficiende lado impulsos e esforços momen-

temente. Ao binômio Universidade/Estado acrescemos a empresa, que se utilizando das pesquisas da Universidade sob a orientação do Estado pelo disciplinamento conduz a Nação ao pleno desenvolvimento.

Um passo importante para Atualização Administrativa será a inteira adoção da carreira do servidor público, que uma vez treinado e formado encontrará estímulo para permanecer no serviço público, acumulando experiências para na ação e gestão da coisa pública alcançar os objetivos de servir ao cidadão e ao Estado.

Ao entendermos que a Atualização Administrativa tem na formação permanente o início de um processo, assim entendemos que a Universidade, com a presença do Estado, pode modificar os parâmetros de desenvolvimento, tornando o Estado presente na vida econômica e social para alcançarmos o apanágio de País pleno e saciado, no todo e na individualidade de cada um.

\section{Conclusão}

Resumindo os pontos significativos dos momentos da Administração Pública Brasileira a partir de 1930 , levantamos ainda alguns conceitos que somados aos pontos de vista externados, no quadro abaixo pode-se confirmar regras e métodos que se executados, podem conduzir o Brasil à eficiência esperada.

Por definição, segundo Pisani, a Administração de Gestão é geral, ela permanente estável, enquanto que a Administração de Missão é adaptável ao problema, a um tempo e lugar, é localizada e termina quando a missão chega ao fim. Mas tanto a Ad-

QUADRO EVOLITIVO DA ADMINISTKACAO PL BLICA BRASILEIRA A PARTIR DE: 1930

\begin{tabular}{|c|c|c|c|}
\hline ELEMENTOS & REFORMA & MODERNIZAÇĀO & ATUALIZAÇĀO \\
\hline Estrutura & DASP & SEPLAN/SEMOR & SEDAP/PR \\
\hline Administraçào & De Giesıảo & De Missào & Prospectiva \\
\hline $\begin{array}{l}\text { Corporativismo } \\
\text { Dominante }\end{array}$ & $\begin{array}{l}\text { Bacharel em } \\
\text { Direito }\end{array}$ & $\begin{array}{l}\text { Bacharel em } \\
\text { Economia }\end{array}$ & $\begin{array}{l}\text { Formaçăo Mul- } \\
\text { tidisciplinar }\end{array}$ \\
\hline Açàu & Operacional & Tática & Estralégia \\
\hline
\end{tabular}




\section{IDÉIAS}

ministração de Gestão quanto de Missão falta um elemento, cuja soma das partes deve determinar o futuro querido que é representado pela função prospectiva, isto é, determinar o futuro querido, na constância evolutiva dos movimentos exigidos na construção das partes.

As ações predominantes em cada período evidenciavam o nível de pessoal exigido, ficando bastante claro a necessidade de formação permanente para acompanhar as ações estratégicas que variam no tempo e no espaço.

Assim, o Estado será completo e pleno quando pleno e saciado for o indivíduo no seu contexto social.

\section{BIBLIOGRAFIA}

1. SCHULTZ, Theodore W. - Investindo no Povo, Forense Universitária, Rio de Janeiro, 1981.

2. MASSENET, Michel. La Nouvelle Gestion Public. Edition Hommes et Techniques, Paris, 1975.

3. MARCELINO, Gileno. Evolução do Estado e Reforma Administrativa. Série Reforma Administrativa, Vol. 1. SEDAP/PR. Brasília, 1987.

4. MITRAUD, Allyson Darowith et Allii. Panorama da Administração Federal Brasileira e Reforma Administrativa, in: Revista de Administração Pública. F. G. V., Out./Dez., Vol. 11, 1977.

5. MITRAUD et Allii - op. cit.

6. PISANI, Edgard. Administration de Gestion et Mission. In: L' Administration Publique, Armand Colin. Paris. 1971.

\section{FUNCEP/PUBLICAÇÕES}

Um acervo de publicações sobre administração pública. Edições que não são encontradas com facilidade na linha editorial de nossos livreiros.

\section{COLEÇÃO ESTUdOS POLITICOS - EP}

Estender, para além das normas e rotinas administrativas, as preocupações relativas aos problemas da Administração. Ao mesmo tempo apresentar textos produzidos por estudiosos que, no desempenho de suas funções, assumiram papéis importantes nos destinos da nação.

Mínimo de 60 páginas; formato $14,5 \times 20,5 \mathrm{~cm}$; capa: papel chambril 120 gr, 2 cores; plastificada; miolo: papel off-set, $75 \mathrm{gr}$.

TÍTULO CÓdIGO PREÇO

Presidencialismo e Parlamentarismo - José Augusto $301 \quad \mathrm{Cz} \$ 600,00$

O Regime Parlamentarista e a Realidade Brasileira - Tancredo Neves

$302 \quad C z \$ 340,00$

Parlamentarismo ao Alcance de Todos - Raul Pilla

303 Cz\$270,00

Parlamentarismo e Presidencialismo na Realidade Brasileira - Sylvio Romero

304 Cz\$ 420,00

Cartilha do Parlamentarismo - João Camilo de Oliveira Torres

$305 \mathrm{Cz} \$ 360,00$

Pródomos do Governo de Gabinete - Aliomar Baleeiro

O Novo Parlamentarismo Vamireh Chacon

$306 \quad C z \$ 330,00$

307 Cz\$ 370,00

TOTAL Cz\$2.690,00

Coleção EP - 7 volumes: Código 300 preço especial Cz\$ $1.900,00$

Cortesia - Anais dos Seminários: Presidencialismo/Parlamentarismo Nordeste e a Constituinte

Pedidos - Podem ser feitos pelo correio, somente através de cheques, à FUNCEP/PUBLICAÇŐES. Caixa Postal 12-2555 70.610 - Brasília/DF 